\title{
Prolyl oligopeptidase attenuates hepatic stellate cell activation through induction of Smad7 and PPAR- $\gamma$
}

\author{
DA ZHOU ${ }^{1}$, JING WANG ${ }^{1}$, LING-NAN HE $^{1}$, BING-HANG LI ${ }^{1}$, YONG-NIAN DING ${ }^{2}$, \\ YUAN-WEN CHEN $^{1}$ and JIAN-GAO FAN ${ }^{1}$
}

${ }^{1}$ Department of Gastroenterology, Xinhua Hospital, Shanghai Jiaotong University School of Medicine, Shanghai 200092;

${ }^{2}$ Department of Gastroenterology, The Second Affiliated Hospital of Xinjiang Medical University, Urumqi, Xinjiang 830028, P.R. China

Received July 22, 2015; Accepted October 21, 2016

DOI: 10.3892/etm.2017.4033

\begin{abstract}
Prolyl oligopeptidase (POP) is a serine endopeptidase widely distributed in vivo with high activity in the liver. However, its biological functions in the liver have remained largely elusive. A previous study by our group has shown that POP produced $N$-acetyl-seryl-aspartyl-lysyl-proline (AcSDKP) and thereby exerted an anti-fibrogenic effect on hepatic stellate cells (HSCs) in vitro. It was therefore hypothesized that POP may affect the activation state of HSCs and has an important role in liver fibrosis. The HSC-T6 immortalized rat liver stellate cell line was treated with the POP inhibitor S17092 or transfected with recombinant lentivirus to overexpress POP. Cell proliferation and apoptosis were determined using a Cell Counting Kit-8 and flow cytometry, respectively. The activation status of HSCs was determined by examination of the expression of $\alpha$-smooth muscle actin ( $\alpha$-SMA), collagen I, monocyte chemoattractant protein-1 (MCP-1), transforming growth factor (TGF)- $\beta$-Smad signaling and peroxisome proliferator activated receptor- $\gamma($ PPAR- $\gamma)$. Inhibition by S17092 decreased, whereas lentiviral expression increased the activity of POP and cell proliferation, while neither of the treatments affected cell apoptosis. Of note, S17092 significantly increased, whereas POP overexpression decreased the expression of $\alpha$-SMA and MCP-1 without affecting the expression of collagen I and TGF- $\beta 1$. Furthermore, S17092 caused a reduc-
\end{abstract}

Correspondence to: Dr Yuan-Wen Chen or Dr Jian-Gao Fan, Department of Gastroenterology, Xinhua Hospital, Shanghai Jiaotong University School of Medicine, 1665 Kongjiang Road, Shanghai 200092, P.R. China

E-mail: chenyuanwen2136@126.com

E-mail: fattyliver2004@126.com

Key words: prolyl oligopeptidase, hepatic stellate cells, transforming growth factor- $\beta$-Smad signaling, peroxisome proliferator activated receptor- $\gamma$ tion, whereas POP overexpression caused an upregulation of Smad7 protein and PPAR- $\gamma$, but not phosphorylated-Smad2/3 expression. In conclusion, POP attenuated the activation of HSCs through inhibition of TGF- $\beta$ signaling and induction of PPAR- $\gamma$, which may have therapeutic potential in liver fibrosis.

\section{Introduction}

Prolyl oligopeptidase (POP; enzyme ID, EC 3.4.21.26; molecular weight, $80 \mathrm{kDa}$ ), also known as prolyl endopeptidase (Prep), is a serine endopeptidase that hydrolyzes proline-containing peptides shorter than 30 amino acids, specifically at the carboxyl terminal of internal proline residues (1). POP was first discovered in the human uterus in 1971 (2) and later it was detected in a wide range of species and in most tissues of mammals, with the highest enzyme activity generally detected in the brain (2). Several bioactive neuropeptides, such as neurotensin, bradykinin, arginine-vasopressin (AVP), thyrotropin-releasing hormone (TRH), and substance $\mathrm{P}$ (SP), are known to be POP substrates in vitro. However, the functions of POP in peripheral tissues have largely remained unknown (1-4). In the liver, the protein density of POP is low, while its activity is surprisingly high $(5,6)$. It was moderately present in the cytoplasm and nuclei of hepatocytes as well as in the nuclei of Kupffer and hepatic endothelial cells (6), but its biological functions in the liver are not well studied.

Chronic liver diseases caused by various etiologies lead to liver fibrosis, which is characterized by excessive deposition of extracellular matrix (ECM) in the liver (7). The activation of HSCs has been reported to have critical roles in the development of hepatic fibrogenesis (8). It is known that the activated HSCs are the major $\alpha$-smooth muscle actin $(\alpha$-SMA)-producing cells and the principle source of deposited ECM, including collagen I, collagen III and proteoglycans, in liver fibrosis (9-13).

The activation of HSCs is mainly mediated by damaged hepatocyte-derived growth factors, such as transforming growth factor- $\beta$ (TGF- $\beta$ ), platelet-derived growth factor (PDGF), endothelin (ET), fibroblast growth factor (FGF) and connective tissue growth factor (CTGF) (14). Among these 
growth factors, TGF- $\beta 1$ is recognized as a major profibrogenic cytokine by promoting and maintaining HSC activation, proliferation, as well as collagen production and deposition through the TGF- $\beta /$ Smad pathway (15-18).

Peroxisome proliferator activated receptor- $\gamma(\operatorname{PPAR}-\gamma)$ was initially identified as a key regulator of adipogenesis (19), while increasing evidence has confirmed that PPAR- $\gamma$ is a key factor in HSC activation and phenotypic alteration, maintaining HSCs in a quiescent phase, and suppressing the production of type I collagen, $\alpha$-SMA and TGF- $\beta 1$. Thus, PPAR- $\gamma$ has an important role in reducing and preventing liver fibrosis $(20,21)$. PPAR- $\gamma$ can disrupt the TGF- $\beta$ signaling pathway and Smad-dependent promoter activity, directly antagonizes the activation and/or function of Smad3 in fibroblasts without affecting the protein expression of stimulatory Smad3. However, PPAR- $\gamma$ can increase the expression of inhibitory Smad7 (22-24). PPAR- $\gamma$ can also restore the ability of HSCs to accumulate retinyl palmitate, a feature of quiescent HSCs (25-27). Together with a decrease in $\alpha$-SMA expression, re-expression of PPAR- $\gamma$ is thought to be an indicator of attenuated HSC activation and even transition to the quiescent state.

A previous study by our group showed that $N$-acetyl-sery l-aspartyl-lysyl-proline (AcSDKP), a tetrapeptide hydrolyzed from thymosin- $\beta_{4}$ by POP (28), exerts an anti-fibrogenic effect on HSCs in vitro $(29,30)$. Other studies also showed that thymosin- $\beta_{4}$ has a protective effect against carbon tetrachloride-induced acute hepatotoxicity and inhibits HSC activation $(31,32)$. However, whether POP can directly affect the activation of HSCs has remained elusive. POP was found to participate in liver inflammation (33) and regulate hepatocyte proliferation and differentiation $(34,35)$. It was therefore hypothesized that POP may have an important role in regulating the functions of HSCs and inhibiting liver fibrosis.

To test this hypothesis, a pharmacological inhibitor of POP activity, S17092, was employed (36), as well as a lentiviral overexpression method to induce the protein expression of POP in the HSC-T6 immortalized rat liver stellate cell line. The results demonstrated that POP can attenuate HSC activation and may protect against liver fibrosis.

\section{Materials and methods}

Cell culture. HSC-T6, which is an immortalized rat liver stellate cell line that has a stable phenotype and biochemical characteristics compared to primary stellate cells $(13,37)$, was obtained from the Cell Bank of the Chinese Academy of Science (Shanghai, China). HSC-T6 cells were cultured in Dulbecco's modified Eagle's medium (DMEM; Gibco, Thermo Fisher Scientific, Inc., Waltham, MA, USA) supplemented with $10 \%$ fetal bovine serum (FBS; Gibco) in a humidified incubator at $37^{\circ} \mathrm{C}$ with $5 \% \mathrm{CO}_{2}$.

Infection with recombinant lentivirus. A recombinant lentivirus overexpressing POP was constructed by Genechem (Shanghai, China) according to the mRNA sequence of the rat Prep gene in GenBank (NM_031324). Cytomegalovirus-driven green fluorescent protein (GFP) reporter gene, which was included in the recombinant lentivirus, was used for detecting the transduction efficiency. HSC-T6 cells were infected with empty lentivirus (mock) or POP-expressing lentivirus at a multiplicity of infection of $10 \mathrm{in} 1 \mathrm{ml}$ of an enhanced infection solution (Eni.S) containing $5 \mu \mathrm{g} / \mathrm{ml}$ polybrene (an infection enhancer; Genechem) for $12 \mathrm{~h}$.

Cell proliferation assay. The proliferation rate of HSC-T6 cells was detected using a Cell Counting Kit-8 (CCK-8; Dojindo, Shanghai, China) according to the manufacturer's instructions. In brief, HSC-T6 cells were seeded on 96-well plates at a density of $1 \times 10^{3}$ cells per well. After culturing for $24 \mathrm{~h}$, cells were treated with increasing concentrations of S17092 (Sigma; Merck Millipore, Darmstadt, Germany) (0, 5, $10,25,50$ or $100 \mu \mathrm{g} / \mathrm{ml}$ ) or vehicle (dimethyl sulfoxide; Sigma, Merck Millipore) for 24 or 48 h. For viral infection, HSC-T6 cells were seeded at a density of $2 \times 10^{3}$ cells per well, infected with mock-transfected or POP-expressing lentivirus for $12 \mathrm{~h}$, and the transfection mixture was subsequently replaced with normal culture medium and cells were cultured for an additional 24 or 48 h. CCK- 8 stain was added and the absorbance (optical density) at $450 \mathrm{~nm}$ was detected using a microplate reader (uQuant; Biotek, Winooski, VT, USA).

Cell apoptosis detection. Cell apoptosis was determined using an Annexin V-phycoerythrin (PE)/7-aminoactinomycin D (AAD) Apoptosis Detection kit (cat. no. 559763; Becton-Dickinson, San Jose, CA, USA) according to the manufacuturer's instructions. Cells $\left(\sim 2 \times 10^{5}\right)$ seeded on $3.5-\mathrm{cm}$ dishes were treated with $\operatorname{S17092}(0,5$ or $10 \mu \mathrm{g} / \mathrm{ml})$ for $24 \mathrm{~h}$. Cells $\left(\sim 5 \times 10^{4}\right)$ seeded on $3.5-\mathrm{cm}$ dishes were infected with mock-transfected or POP-expressing lentivirus for $12 \mathrm{~h}$, and the transfection mixture was replaced with normal culture medium and cells were cultured for an additional $24 \mathrm{~h}$. Cells were subsequently harvested and stained with Annexin V-PE and 7-AAD at room temperature for $15 \mathrm{~min}$. Apoptotic cells were detected using a FACScan flow cytometer and analyzed by CellQuest software (version 5.1; Becton-Dickinson).

Reverse-transcription quantitative polymerase chain reaction $(R T-q P C R)$. Total RNA was extracted from treated cells using TRIzol (Takara Bio Inc., Dalian, China) and was reverse-transcribed into complementary DNA using primescript RT master mix (cat. no. RR036A; Takara Bio Inc.) under the following conditions: $37^{\circ} \mathrm{C}$ for $15 \mathrm{~min}, 85^{\circ} \mathrm{C}$ for $5 \mathrm{sec}$ and $4^{\circ} \mathrm{C} 1 \mathrm{~h}$. qPCR was performed in a 7500 Real-time PCR system (Applied Biosystems; Thermo Fisher Scientific, Inc.) using the SYBR Premix Ex Taq (Tli RnaseH Plus; cat. no. RR420A; Takara Bio, Inc.) under the following conditions: $95^{\circ} \mathrm{C}$ for $30 \mathrm{sec}, 95^{\circ} \mathrm{C}$ for $5 \mathrm{sec}$ and $60^{\circ} \mathrm{C}$ for $34 \mathrm{sec}(40$ cycles), $95^{\circ} \mathrm{C}$ for $15 \mathrm{sec}, 60^{\circ} \mathrm{C}$ for $1 \mathrm{~min}, 95^{\circ} \mathrm{C}$ for $15 \mathrm{sec}$ and $60^{\circ} \mathrm{C}$ for $15 \mathrm{sec}$. Primers of target genes were synthesized by Sangon Biotech (Shanghai, China) and their sequences are listed in Table I. Primer specificity was confirmed by a dissociation curve using 7500 system SDS software (Applied Biosystems). GAPDH was used as the internal control (38).

Western blot analysis. Treated cells were lysed in ice-cold radio-immunoprecipitation assay (RIPA) buffer containing protease and phosphatase inhibitor phenylmethylsulfonyl fluoride (PMSF; Beyotime Institute of Biotechnology, Shanghai, China). Total protein was measured using the bicinchoninic acid protein assay (Beyotime Institute of Biotechnology). Mouse 
Table I. Primers for real-time polymerase chain reaction.

\begin{tabular}{|c|c|c|}
\hline Gene & GenBank ID & Primers \\
\hline TGF- $\beta 1$ & NM_021578.2 & $\begin{array}{l}\text { Forward: 5'-ATTCCTGGCGTTACCTTGG-3' } \\
\text { Reverse: 5'-AGCCCTGTATTCCGTCTCCT-3' }\end{array}$ \\
\hline$\alpha$-SMA & NM_031004.2 & $\begin{array}{l}\text { Forward: 5'-TGTGCTATGTCGCTCTGGAC-3' } \\
\text { Reverse: 5'-CCAATGAAAGATGGCTGGAA-3' }\end{array}$ \\
\hline MCP-1 & NM_031530.1 & $\begin{array}{l}\text { Forward: 5'-CCCAGAAACCAGCCAACT-3' } \\
\text { Reverse: 5'-CCAGTGAATGAGTAGCAGCAG-3' }\end{array}$ \\
\hline POP & NM_031324 & $\begin{array}{l}\text { Forward: 5'-AGTGCCGTTTCTTGAGCAGT-3' } \\
\text { Reverse: 5'-CGTCATCCGACAGAGTGTTG-3' }\end{array}$ \\
\hline Col1a1 & NM_053304.1 & $\begin{array}{l}\text { Forward: 5'-TATCTGCCACAATGGCACGG-3' } \\
\text { Reverse: 5'-GCACGGAAACTCCAGCTGAT-3' }\end{array}$ \\
\hline GAPDH & NM_017008.4 & $\begin{array}{l}\text { Forward: 5'-GGGCAGCCCAGAACATCAT-3' } \\
\text { Reverse: 5'-CCAGTGAGCTTCCCGTTCAG-3' }\end{array}$ \\
\hline
\end{tabular}

POP, prolyl oligopeptidase; TGF, transforming growth factor; SMA, smooth muscle actin; MCP, monocyte chemoattractant protein; Col1a1, collagen type I $\alpha 1$ chain.

anti- $\alpha$-SMA (cat. no. A5228; $1: 1,000$ ), rabbit anti-TGF- $\beta 1$ (cat. no. SAB4502954; 1:1,000) and rabbit anti-POP (cat. no. SAB2104515; 1:500) were purchased from Sigma (Merck Millipore), while rabbit anti-Smad7 (cat. no. D160746; 1:1,000), rabbit anti-PPAR- $\gamma$ (cat. no. AB61087; 1:1,000) were obtained from Sangon Biotech (Shanghai, China), rabbit anti-phosphorylated (p)-Smad 2/3 (cat. no. AP0326; 1:1,000) was purchased from Bioworld Technology (St. Louis Park, MN, USA), and mouse anti-beta tubulin (cat.no. AT819; 1:1,000) was purchased from Beyotime Institute of Biotechnology (Shanghai, China). A secondary horseradish peroxidase-conjugated goat anti-mouse antibody (cat. no. A9917; 1:60,000) and goat anti-rabbit antibody (cat. no. A9169; 1:50,000) were purchased from Sigma (Merck Millipore). Western blot analysis was performed as previously described (29). Immune complexes were detected using immobilon western chemiluminescent horseradish peroxidase substrate (Millipore Corp., Billerica, MA, USA). Bands were quantified using Image Lab version 2.0.1 (Bio-Rad Laboratories, Hercules, CA, USA). Tubulin was used as a loading control.

POP activity assay. Intracellular AcSDKP was measured using the AcSDKP enzyme immunoassay kit (Bertin Pharma, Montigny-le-Bretonneux, France) modified for the cells $(29,39)$. In brief, cells were lysed with RIPA buffer containing $10 \mu \mathrm{mol} / 1$ captopril and $1 \mathrm{mmol} / 1 \mathrm{PMSF}$. The cell number was determined using a Fuchs-Rosenthal counting chamber. Lysates were centrifuged at $14,000 \mathrm{x}$ g for $10 \mathrm{~min}$ and supernatants were extracted with methanol. Samples and standards were then processed according to the manufacturer's instructions.

Statistical analysis. Results were expressed as the mean \pm standard error of the mean. At least three independent experiments were performed for each assay. Data were analyzed by Student's t-test or one way analysis of variance followed by the Mann-Whitney U test using SAS software (Release 8.02
TS Level 02 M0; SAS Institute, Cary, NC, USA). P<0.05 was considered to indicate a statistically significant difference.

\section{Results}

Pharmacological inhibition of POP activity and lentiviral induction of POP protein expression in HSC-T6 cells. As a potent inhibitor of POP, S17092 has been considered as a promising therapeutic compound for memory impairment (40). In the present study, the effects of S17092 on HSC-T6 cells were investigated. S17092 treatment did not affect the protein levels of POP (Fig. 1A); however, it dose-dependently decreased the activity of POP as indicated by the intracellular levels of AcSDKP (Fig. 1B). To induce the activity of POP, HSC-T6 cells were transfected with a lentiviral overexpression vector. The protein levels of POP in HSC-T6 cells transduced with POP overexpression vector were $\sim 2.5$-fold increased compared with those in mock-transfected and non-transfected control HSC-T6 cells (Fig. 1C). Consistently, the intracellular levels of AcSDKP were 1.5 -fold increased, indicating that POP activity was increased (Fig. 1D). Of note, after transduction with POP-expressing lentivirus, the mRNA levels of POP were $\sim 8$-fold increased compared to those in mock- and non-transfected control HSC-T6 cells (Fig. 1E). These results showed that POP activity in HSC-T6 cells can be pharmacologically inhibited or induced using a lentivirus.

POP activity is essential for the proliferation of HSC-T6 cells but does not affect apoptosis. To investigate the effect of POP on the growth of HSC-T6 cells, cell proliferation and apoptosis were tested under pharmacological inhibition and lentiviral induction conditions. S17092 inhibited the proliferation of HSC-T6 cells in a dose-dependent manner (Fig. 2A), whereas POP overexpression promoted cell proliferation by $80 \%$ compared to mock- and non-transfected control HSC-T6 cells after $48 \mathrm{~h}$ of incubation $(\mathrm{P}<0.05)$ (Fig. 2B). However, S17092 or lentiviral induction of POP did not 


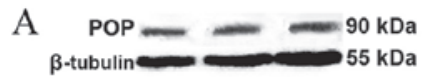

B

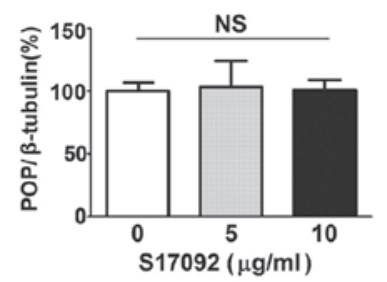

C POP $90 \mathrm{kDa}$
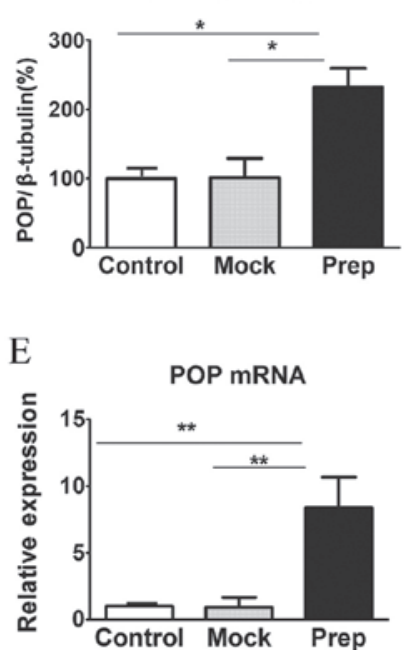

Figure 1. POP activity inhibition by S17092 and overexpression by lentivirus in HSC-T6 cells. (A) Western blot analysis of POP protein and (B) determination of intracellular Ac-SDKP levels in HSC-T6 cells after treatment with various concentrations of POP inhibitor S17092 $(0,5$ or $10 \mu \mathrm{g} / \mathrm{ml})$. (C) Western blot analysis of POP protein, (D) determination of intracellular Ac-SDKP levels and (E) POP mRNA expression in HSC-T6 cells after infection with prep-or mock-lentivirus for 3 days determined by quantitative polymerase chain reaction analysis. Values are normalized to tubulin. ${ }^{*} \mathrm{P}<0.05,{ }^{* *} \mathrm{P}<0.01$. NS, not significant; POP, prolyl oligopeptidase; Ac-SDKP, $N$-acetyl-seryl-aspartyl-lysyl-proline.

affect the apoptotic rate of HSC-T6 cells (Fig. 2C and D). These results suggested that POP increases the proliferation of HSCs in vitro.

POP inhibits the expression of $\alpha$-SMA and MCP-1 without affecting collagen I and TGF- $\beta 1$. To assess the potential influence of POP on liver fibrosis, several markers for the activation of HSCs were tested after pharmacological inhibition or lentiviral induction of POP. Compared with the vehicle, S17092 dose-dependently increased the mRNA expression of $\alpha$-SMA and MCP-1 in HSC-T6 cells at the concentration of 5 and $10 \mu \mathrm{g} / \mathrm{ml}$ without affecting collagen I and TGF- $\beta 1$ mRNA expression (Fig. 3A). By contrast, POP overexpression in HSC-T6 resulted in a significant decrease in the expression of $\alpha$-SMA and MCP-1 mRNA but not of collagen I and TGF- $\beta 1$ mRNA when compared to mock- and non-transfected control HSC-T6 cells (Fig. 3B). Western blot analysis further confirmed that the protein levels of $\alpha$-SMA were dose-dependently increased by S17092 and significantly decreased after lentiviral induction (Fig. 3C). However, the protein levels of TGF- $\beta 1$ were not affected by either S17092 or
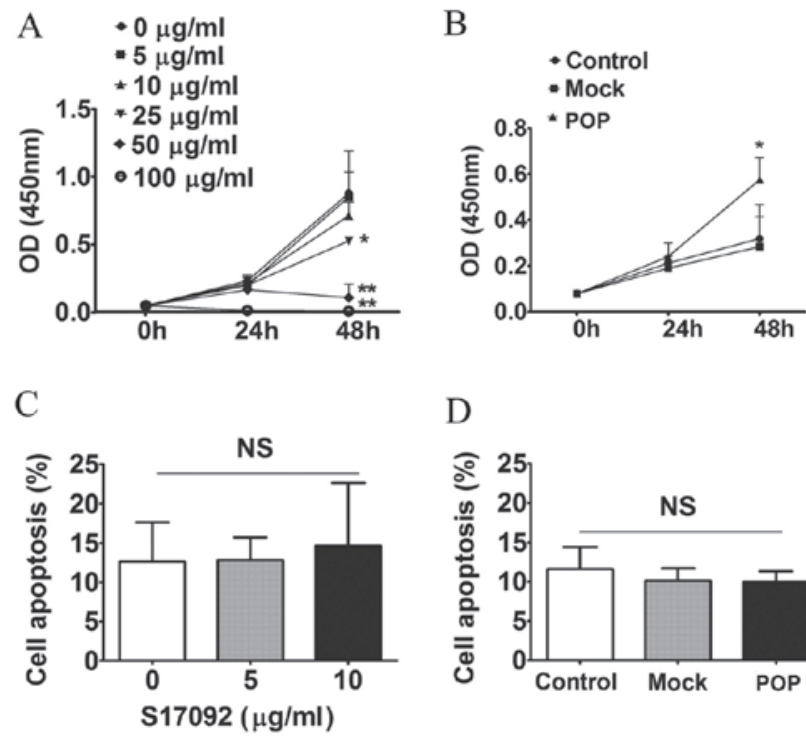

$\mathrm{D}$

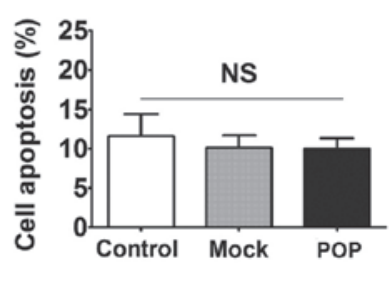

Figure 2. Cell prolifeation and apoptosis after POP inhibiton or overexpresion in HSC-T6 cells. Effects of (A) various concentrations of POP-inhibitor S17092 or (B) lentivirus-mediated overexpression of POP in HSC-T6 cells as determined using a Cell Counting Kit- 8 . The OD at $450 \mathrm{~nm}$ is proportional to the number of viable cells. Cell apoptosis after (C) treatment with S17092 $(0,5$ or $10 \mu \mathrm{g} / \mathrm{ml})$ for $24 \mathrm{~h}$ or (D) transduction with mock-transfected or POP-expressing lentivirus for 3 days. ${ }^{*} \mathrm{P}<0.05,{ }^{* * *} \mathrm{P}<0.01$ vs. control group. NS, not significant; POP, prolyl oligopeptidase; OD, optical density; mock, empty lentivirus.
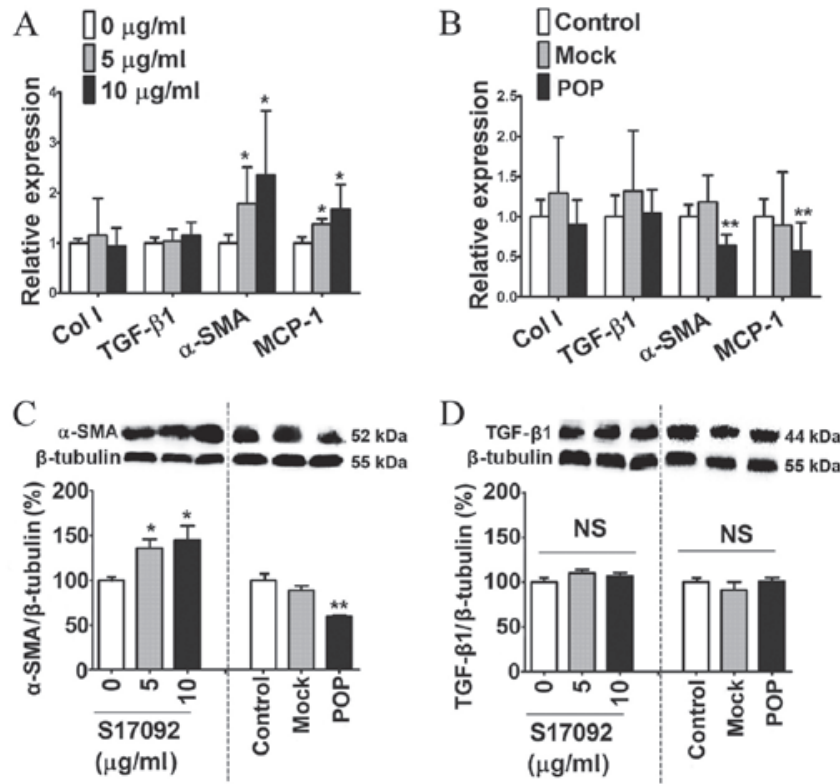

Figure 3. Effects of POP on the activation status and fibrogenic properties of HSC-T6 cells. mRNA expression levels of $\alpha$-SMA, collagen I, MCP-1 and TGF- $\beta 1$ in HSC-T6 cells (A) treated with S17092 (0, 5 or $10 \mu \mathrm{g} / \mathrm{ml})$ for $24 \mathrm{~h}$ or (B) infected with mock- or POP-expressing lentivirus for 3 days. Western blot analysis of (C) $\alpha$-SMA and (D) TGF- $\beta 1$ in HSC-T6 cells treated with S17092 $(0,5$ or $10 \mu \mathrm{g} / \mathrm{ml})$ for $24 \mathrm{~h}$ or transduced with mock-transfected or POP-expressing lentivirus for 3 days. ${ }^{*} \mathrm{P}<0.05,{ }^{* * *} \mathrm{P}<0.01$. NS, not significant. TGF, transforming growth factor; SMA, smooth muscle actin; MCP, monocyte chemoattractant protein; POP, prolyl oligopeptidase mock, empty lentivirus.

lentiviral vector. These results indicated that POP reduces the expression of pro-fibrotic genes. 
A
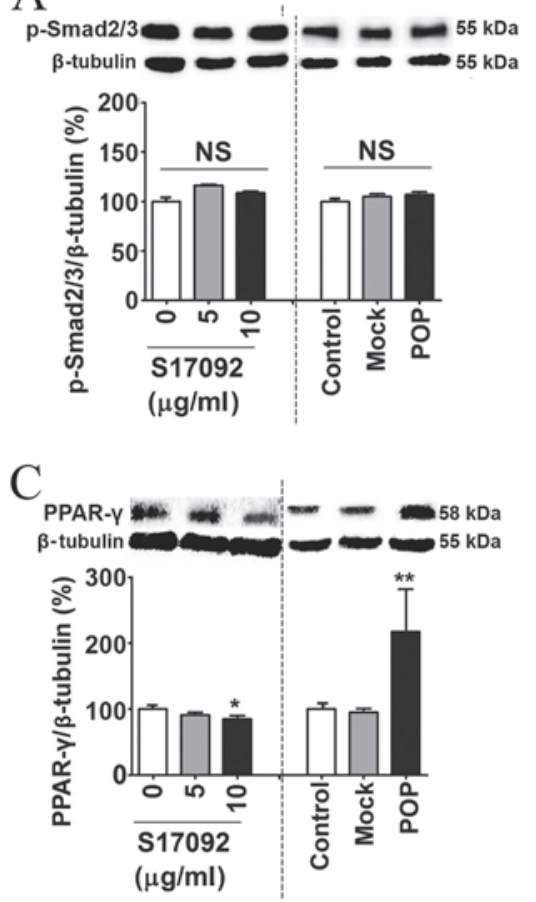

B

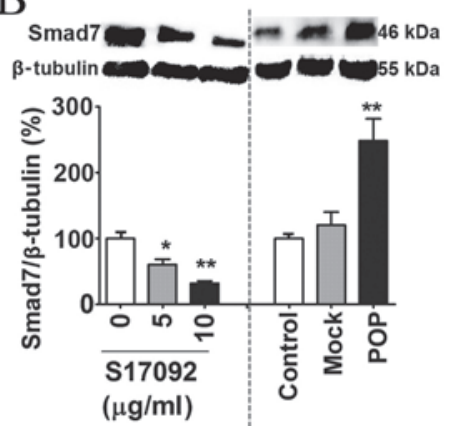

Figure 4. Effects of POP on Smad proteins and PPAR- $\gamma$ signaling in HSC-T6 cells. Western blot analysis of (A) p-Smad 2/3, (B) Smad7 and (C) PPAR- $\gamma$ in HSC-T6 cells treated with $\mathrm{S} 17092(0,5$ or $10 \mu \mathrm{g} / \mathrm{ml})$ for $24 \mathrm{~h}$ or transduced with mock-transfected or POP-expressing lentivirus for 3 days. ${ }^{*} \mathrm{P}<0.05,{ }^{* *} \mathrm{P}<0.01$. NS, not significant; POP, prolyl oligopeptidase; PPAR, peroxisome proliferator activated receptor; p-Smad, phosphorylated Smad; mock, empty lentivirus.

POP increases Smad7 and PPAR- $\gamma$ without affecting $p$-Smad 2/3. Smad proteins are intracellular mediators of the signal transduction of TGF- $\beta$ (41). The protein levels of p-Smad2/3 were not affected by either S17092 treatment or POP overexpression (Fig. 4A). However, the Smad7 protein was significantly downregulated in S17092-treated cells (Fig. 4B). By contrast, Smad7 was significantly upregulated in lentivirus-induced cells compared to mock- and non-transfected control HSC-T6 cells (Fig. 4B). Of note, PPAR- $\gamma$ was also markedly decreased following S17092 treatment and increased in following lentiviral induction (Fig. 4C). These results showed that POP affects the Smad7 and PPAR- $\gamma$ signaling pathways.

\section{Discussion}

The present study showed that POP attenuated the activation of HSC-T6 cells, as indicated by the inhibited expression of MCP-1 and $\alpha$-SMA. This activated phenotype may be caused by increased Smad7 and PPAR- $\gamma$ levels.

Liver fibrosis is associated with complex molecular and cellular mechanisms, while HSCs are considered to have a pivotal role in this process, mainly participating in intrahepatic inflammation and excessive deposition of ECM in the liver $(15,42)$. The results of the present study showed that POP decreased $\alpha$-SMA, which is a marker for HSC activation. Furthermore, in HSC-T6 cells, POP also inhibited MCP-1, which is a crucial pro-inflammatory and pro-fibrotic cytokine mainly produced by activated HSCs in the liver (43). These results suggested that POP attenuates HSC activation and thus their pro-fibrotic features.

TGF- $\beta$ signaling is critical in promoting liver fibrosis $(15,16)$. While, according to the results of the present study, inhibition by S17902 and POP overexpression did not affect TGF- $\beta 1$ expression and $p$-Smad2/3 levels in HSC-T6 cells, POP participated in the regulation of Smad7 levels. Following POP inhibition, Smad7 was decreased, while it was increased after POP overexpression. These data suggested an inhibitory effect of POP on TGF- $\beta 1$ signaling. Smad7 is an inhibitory peptide, which blocks TGF- $\beta 1$ signaling by physical interaction with the activated TGF- $\beta$ receptor 1 and prevention of the docking and phosphorylation of $\operatorname{Smad} 2 / 3$, thus inhibiting its pro-fibrogenic and pro-inflammatory activities and HSC activation $(44,45)$.

Apart from de novo expression of $\alpha$-SMA, reduced PPAR- $\gamma$ expression is also a marker for HSC activation $(20,21)$. The results of the present study showed that POP inhibitor significantly decreased, while lentivirus-mediated overexpression of POP increased the expression of PPAR- $\gamma$. Together with decreased $\alpha$-SMA levels in HSCs, this indicated attenuated HSC activation.

The decrease of intracellular Ac-SDKP after POP inhibition by $\mathrm{S} 17092$ as well as the increase of intracellular Ac-SDKP after vector-mediated overexpression of POP demonstrated that POP activity was successfully manipulated in HSC-T6 cells. It may be speculated that the effects of POP on HSCs may be mediated via Ac-SDKP, since a previous study has demonstrated the anti-inflammatory and anti-fibrotic effects of Ac-SDKP on HSCs (29). However, there are differences between the effects of POP and Ac-SDKP on HSCs. In the present study, POP inhibited TGF- $\beta 1$ signaling via increasing Smad7 without affecting TGF- $\beta 1$ and $\mathrm{p}-\mathrm{Smad} 2 / 3$. This effect is different from that of Ac-SDKP, which decreases the expression of TGF- $\beta 1$ and p-Smad2/3 without affecting Smad7 (29). Furthermore, Ac-SDKP inhibits HSC proliferation (29), 
which is in contrast to the stimulatory effect of POP on the proliferation of HSCs, as shown by decreased cell proliferation after POP inhibition and increased cell proliferation after POP overexpression in the present study. Indeed, this difference has also been shown in other cell types, such as cancer cells and nervous tissue (46-48). In fact, POP was found to be important in promoting hepatocyte proliferation and liver regeneration $(34,49,50)$. The effect may be mediated by POP present in cell nuclei, and to not be associated with its catalytic activity but with protein-protein interactions to regulate gene expression and protein secretion $(35,51-53)$. It has been reported that POP binds to growth-associated protein 43 to control growth cone and synaptic function (46). Of note, HSC activation is generally characterized by increased expression of $\alpha$-SMA and proliferation (54). However, after activation, $\alpha$-SMA expression in HSCs in the S-phase of the cell cycle is low or not present (55). Recent studies showed that POP inhibitors impeded cell growth via reducing the expression of retinoblastoma protein $(\mathrm{pRb})$ and Ki-67 and increasing the expression of p53, p27 ${ }^{\mathrm{kip} 1}$ and pRb2/ p130 in cancer cells $(47,48)$. Collectively, the effects of POP on HSCs may not or not exclusively be due to increases in Ac-SDKP. However, it is difficult to separate the effects of POP and Ac-SDKP on HSCs since the mechanisms of the effect of Ac-SDKP on HSCs are currently elusive and no inhibitor or reliable neutralizing antibody is available to investigate these.

In conclusion, the present study showed that POP attenuated HSC activation and decreased its pro-inflammatory and pro-fibrotic features, strongly suggesting a protective effect of POP against liver fibrosis. Further studies are required to investigate specific mechanisms of POP in regulating HSC proliferation and activation and its possible anti-fibrotic effect in vivo.

\section{Acknowledgements}

This study was supported by the National Natural Science Foundation of China (grant nos. 81170,410 to Y.-W.C., 81260081 to Y.-N.D., and 81070322 to J.-G.F.), the New Talented Young Medical Specialist Cultivating Program of Shanghai (no. XYQ2011010 to Y.-W.C.), the Key Research Program for Colleges and Universities of Xinjiang Uygur Autonomous Region (no. XJEDU2012I001 to Y.-N.D.), and by the State Key Development Program for Basic Research of China (no. 2012CB517501 to J.-G.F.).

\section{References}

1. Gass J and Khosla C: Prolyl endopeptidases. Cell Mol Life Sci 64: 345-355, 2007.

2. Walter R, Shlank H, Glass JD, Schwartz IL and Kerenyi TD: Leucylglycinamide released from oxytocin by human uterine enzyme. Science 173: 827-829, 1971.

3. Irazusta J, Larrinaga G, González-Maeso J, Gil J, Meana JJ and Casis L: Distribution of prolyl endopeptidase activities in rat and human brain. Neurochem Int 40: 337-345, 2002.

4. Myöhänen TT, Venäläinen JI, Garcia-Horsman JA, Piltonen M and Männistö PT: Cellular and subcellular distribution of rat brain prolyl oligopeptidase and its association with specific neuronal neurotransmitters. J Comp Neurol 507: 1694-1708, 2008.

5. Myohanen TT, Pyykkö E, Männistö PT and Carpen O: Distribution of prolyl oligopeptidase in human peripheral tissues and in ovarian and colorectal tumors. J Histochem Cytochem 60: 706-715, 2012
6. Myohanen TT, Venäläinen JI, García-Horsman JA, Piltonen M and Männistö PT: Distribution of prolyl oligopeptidase in the mouse whole-body sections and peripheral tissues. Histochem Cell Biol 130: 993-1003, 2008.

7. Sakata K, Eda S, Lee ES, Hara M, Imoto M and Kojima S: Neovessel formation promotes liver fibrosis via providing latent transforming growth factor- $\beta$. Biochem Biophys Res Commun 443: 950-956, 2014.

8. Yu FX, Teng YY, Zhu QD, Zhang QY and Tang Y: Inhibitory effects of capsaicin on hepatic stellate cells and liver fibrosis. Biochem Cell Biol 92: 406-412, 2014.

9. Friedman SL: Evolving challenges in hepatic fibrosis. Nat Rev Gastroenterol Hepatol 7: 425-436, 2010.

10. Atzori L, Poli G and Perra A: Hepatic stellate cell: A star cell in the liver. Int J Biochem Cell Biol 41: 1639-1642, 2009.

11. Wallace K, Burt Alastair AD and Wright Matthew MC: Liver fibrosis. Biochemical J 411: 1-18, 2008.

12. Yu F, Su L, Ji S, Zhang S, Yu P, Zheng Y and Zhang Q: Inhibition of hepatic stellate cell activation and liver fibrosis by fat-specific protein 27. Mol Cell Biochem 369: 35-43, 2012.

13. Friedman SL: Hepatic stellate cells: Protean, multifunctional and enigmatic cells of the liver. Physiol Rev 88: 125-172, 2008.

14. Borg BB, Seetharam A, Subramanian V, Basha HI, Lisker-Melman M, Korenblat K, Anderson CD, Shenoy S, Chapman WC, Crippin JS and Mohanakumar T: Immune response to extracellular matrix collagen in chronic hepatitis C-induced liver fibrosis. Liver Transpl 17: 814-823, 2011.

15. Lee SJ, Kim KH and Park KK: Mechanisms of fibrogenesis in liver cirrhosis: The molecular aspects of epithelial-mesenchymal transition. World J Hepatol 6: 207-216, 2014.

16. Hills CE and Squires PE: The role of TGF- $\beta$ and epithelial-to mesenchymal transition in diabetic nephropathy. Cytokine Growth Factor Rev 22: 131-139, 2011.

17. Dooley S, Delvoux B, Lahme B, Mangasser-Stephan K and Gressner AM: Modulation of transforming growth factor beta response and signaling during transdifferentiation of rat hepatic stellate cells to myofibroblasts. Hepatology 31: 1094-1106, 2000.

18. Nakao A, Afrakhte M, Morén A, Nakayama T, Christian JL, Heuchel R, Itoh S, Kawabata M, Heldin NE, Heldin CH and ten Dijke P: Identification of Smad7, a TGFbeta-inducible antagonist of TGF-beta signalling. Nature 389: 631-635, 1997.

19. Chawla A, Repa JJ, Evans RM and Mangelsdorf DJ: Nuclear receptors and lipid physiology: Opening the X-files. Science 294: 1866-1870, 2001.

20. Zardi EM, Navarini L, Sambataro G, Piccinni P, Sambataro FM, Spina $C$ and Dobrina A: Hepatic PPARs: Their role in liver physiology, fibrosis and treatment. Curr Med Chem 20: 3370-3396, 2013.

21. Yu J,Zhang S, Chu ES, Go MY, Lau RH, Zhao J, Wu CW, Tong L, Zhao J, Poon TC and Sung JJ: Peroxisome proliferator-activated receptors gamma reverses hepatic nutritional fibrosis in mice and suppresses activation of hepatic stellate cells in vitro. Int J Biochem Cell Biol 42: 948-957, 2010.

22. Bian D, Zhang J, Wu X, Dou Y, Yang Y, Tan Q, Xia Y, Gong Z and Dai Y: Asiatic acid isolated from Centella asiatica inhibits TGF- $\beta 1$-induced collagen expression in human keloid fibroblasts via PPAR- $\gamma$ activation. Int J Biol Sci 9: 1032-1042, 2013.

23. Jeon KI, Kulkarni A, Woeller CF, Phipps RP, Sime PJ, Hindman HB and Huxlin KR: Inhibitory effects of PPAR $\gamma$ ligands on TGF- $\beta 1$-induced corneal myofibroblast transformation. Am J Pathol 184: 1429-1445, 2014.

24. Ghosh AK, Bhattacharyya S, Lakos G, Chen SJ, Mori Y and Varga J: Disruption of transforming growth factor beta signaling and profibrotic responses in normal skin fibroblasts by peroxisome proliferator-activated receptor gamma. Arthritis Rheum 50: 1305-1318, 2004.

25. Blaner WS, O'Byrne SM, Wongsiriroj N, Kluwe J, D'Ambrosio DM, Jiang H, Schwabe RF, Hillman EM, Piantedosi R and Libien J: Hepatic stellate cell lipid droplets: A specialized lipid droplet for retinoid storage. Biochim Biophys Acta 1791: 467-473, 2009.

26. Park S, Choi S, Lee MG, Lim C and Oh J: Retinol binding protein-albumin domain III fusion protein deactivates hepatic stellate cells. Mol Cells 34: 517-522, 2012.

27. Kluwe J, Wongsiriroj N, Troeger JS, Gwak GY, Dapito DH, Pradere JP, Jiang H, Siddiqi M, Piantedosi R, O'Byrne SM, et al: Absence of hepatic stellate cell retinoid lipid droplets does not enhance hepatic fibrosis but decreases hepatic carcinogenesis. Gut 60: 1260-1268, 2011. 
28. Cavasin MA, Rhaleb NE, Yang XP and Carretero OA: Prolyl Oligopeptidase is involved in release of the Antifibrotic peptide Ac-SDKP. Hypertension 43: 1140-1145, 2004.

29. Chen YW, Liu BW, Zhang YJ, Chen YW, Dong GF, Ding XD, Xu LM, Pat B, Fan JG and Li DG: Preservation of basal AcSDKP attenuates carbon tetrachloride-induced fibrosis in the rat liver. J Hepatol 53: 528-536, 2010.

30. Zhang L, Xu LM, Chen YW, Ni QW, Zhou M, Qu CY and Zhang Y: Antifibrotic effect of N-acetyl-seryl-aspartyl-lysyl-p roline on bile duct ligation induced liver fibrosis in rats. World J Gastroenterol 18: 5283-5288, 2012.

31. Xiao Y, Qu C, Ge W, Wang B, Wu J, Xu L and Chen Y: Depletion of thymosin $\beta 4$ promotes the proliferation, migration and activation of human hepatic stellate cells. Cell Physiol Biochem 34: 356-367, 2014

32. Reyes-Gordillo K, Shah R, Arellanes-Robledo J, Rojkind M and Lakshman MR: Protective effects of thymosin $\beta 4$ on carbon tetrachloride-induced acute hepatotoxicity in rats. Ann N Y Acad Sci 1269: 61-68, 2012.

33. Nozaki Y, Sato N, Iida T, Hara K, Fukuyama K and Epstein WL: Prolyl endopeptidase purified from granulomatous inflammation in mice. J Cell Biochem 49: 296-303, 1992.

34. Yamakawa N, Shimeno H, Soeda S and Nagamatsu A: Regulation of prolyl oligopeptidase activity in regenerating rat liver. Biochim Biophys Acta 1199: 279-284, 1994.

35. Tenorio-Laranga J, Männistö PT, Storvik M, Van der Veken P and García-Horsman JA: Four day inhibition of prolyl oligopeptidase causes significant changes in the peptidome of rat brain, liver and kidney. Biochimie 94: 1849-1859, 2012.

36. Bellemère G, Morain P, Vaudry $\mathrm{H}$ and Jégou S: Effect of $\mathrm{S}$ 17092, a novel prolyl endopeptidase inhibitor, on substance P and alpha-melanocyte-stimulating hormone breakdown in the rat brain. J Neurochem 84: 919-929, 2003.

37. Vogel S, Piantedosi R, Frank J, Lalazar A, Rockey DC, Friedman SL and Blaner WS: An immortalized rat liver stellate cell line (HSC-T6): A new cell model for the study of retinoid metabolism in vitro. J Lipid Res 41: 882-893, 2000.

38. Livak KJ and Schmittgen TD: Analysis of relative gene expression data using real-time quantitative PCR and the 2(-Delta Delta C(T)) method. Methods 25: 402-408, 2001.

39. Liu JM, Lawrence F, Kovacevic M, Bignon J, Papadimitriou E, Lallemand JY, Katsoris P, Potier P, Fromes Y and WdzieczakBakala J: The tetrapeptide AcSDKP, an inhibitor of primitive hematopoietic cell proliferation, induces angiogenesis in vitro and in vivo. Blood 101: 3014-3020,2003.

40. Morain P, Lestage P, De Nanteuil G, Jochemsen R, Robin JL, Guez D and Boyer PA: S 17092: A prolyl endopeptidase inhibitor as a potential therapeutic drug for memory impairment Preclinical and clinical studies. CNS Drug Rev 8: 31-52, 2002.

41. Inagaki Y and Okazaki I: Emerging insights into Transforming growth factor beta Smad signal in hepatic fibrogenesis. Gut 56 284-292, 2007.
42. Choi SS and Diehl AM: Epithelial-to-mesenchymal transitions in the liver. Hepatology 50: 2007-2013, 2009.

43. Marra F and Tacke F: Roles for chemokines in liver disease. Gastroenterology 147: 577-594, 2014.

44. Pohlers D, Brenmoehl J, Löffler I, Müller CK, Leipner C, Schultze-Mosgau S, Stallmach A, Kinne RW and Wolf G: TGF-beta and fibrosis in different organs-molecular pathway imprints. Biochim Biophys Acta 1792: 746-756, 2009.

45. Miyazono K, ten Dijke P and Heldin CH: TGF-beta signaling by Smad proteins. Adv Immunol 75: 115-157, 2000.

46. Di Daniel E, Glover CP, Grot E, Chan MK, Sanderson TH, White JH, Ellis CL, Gallagher KT, Uney J, Thomas J, et al: Prolyl oligopeptidase binds to GAP-43 and functions without its peptidase activity. Mol Cell Neurosci 41: 373-382, 2009.

47. Suzuki K, Sakaguchi M, Tanaka S, Yoshimoto T and Takaoka M: Prolyl oligopeptidase inhibition-induced growth arrest of human gastric cancer cells. Biochem Biophys Res Commun 443: 91-96, 2014.

48. Sakaguchi M, Matsuda T, Matsumura E, Yoshimoto T and Takaoka M: Prolyl oligopeptidase participates in cell cycle progression in a human neuroblastoma cell line. Biochem Biophys Res Commun 409: 693-698, 2011.

49. Agirregoitia N, Casis L, Gil J, Ruiz F and Irazusta J: Ontogeny of prolyl endopeptidase and pyroglutamyl peptidase I in rat tissues. Regul Pept 139: 52-58, 2007.

50. Matsubara Y, Ono T, Tsubuki S, Irie S and Kawashima S: Transient up-regulation of a prolyl endopeptidase activity in the microsomal fraction of rat liver during postnatal development. Eur J Biochem 252: 178-183, 1998.

51. Myöhänen TT, García-Horsman JA, Tenorio-Laranga J and Männistö PT: Issues about the physiological functions of prolyl oligopeptidase based on its discordant spatial association with substrates and inconsistencies among mrna, protein levels and enzymatic activity. J Histochem Cytochem 57: 831-848, 2009.

52. Tenorio-Laranga J, Männistö PT and García-Horsman JA: Hunting for peptide substrates of prolyl oligopeptidase: Classical versus non-classical bioactive peptides. CNS Neurol Disord Drug Targets 10: 319-326, 2011.

53. Matsuda T, Sakaguchi M, Tanaka S, Yoshimoto T and Takaoka M: Prolyl oligopeptidase is a glyceraldehyde-3-phosphate dehydrogenase-binding protein that regulates genotoxic stress-induced cell death. Int J Biochem Cell Biol 45: 850-857, 2013.

54. Moreira RK: Hepatic stellate cells and liver fibrosis. Arch Pathol Lab Med 131: 1728-1734, 2007.

55. Mashimo Y, Mochida S, Inao M, Yamaoka M, Nagoshi S, Matsui A and Fujiwara K: Decreased expression of smooth muscle $\alpha$ actin in activated rat hepatic stellate cells at the S-phase of the cell cycle in vitro. Hepatol Res 15: 22-31, 1999. 